Intersections

Canadian Journal of Music

Revue canadienne de musique
Intersections

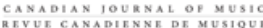

\title{
La musique populaire : vers une économie du don
}

\section{Sophie Stévance}

Volume 30, numéro 2, 2010

URI : https://id.erudit.org/iderudit/1006374ar

DOI : https://doi.org/10.7202/1006374ar

Aller au sommaire du numéro

Éditeur(s)

Canadian University Music Society / Société de musique des universités canadiennes

ISSN

1911-0146 (imprimé)

1918-512X (numérique)

Découvrir la revue

Citer ce document

Stévance, S. (2010). La musique populaire : vers une économie du don.

Intersections, 30(2), 3-4. https://doi.org/10.7202/1006374ar

All Rights Reserved (C Canadian University Music Society / Société de musique des universités canadiennes, 2011
Ce document est protégé par la loi sur le droit d'auteur. L'utilisation des services d’Érudit (y compris la reproduction) est assujettie à sa politique d'utilisation que vous pouvez consulter en ligne.

https://apropos.erudit.org/fr/usagers/politique-dutilisation/ 


\title{
ÉDITORIAL : LA MUSIQUE POPULAIRE : VERS UNE ÉCONOMIE DU DON
}

\author{
Sophie Stévance
}

Alors que la musique populaire prend une place légitime au sein des programmes d'études supérieures, elle demeure cependant, et dans une large mesure, l'objet des sciences sociales. Tantôt ignorée, tantôt décriée par une part de la musicologie traditionnelle qui lui reproche entre autres ses «stimuli sensibles» (Adorno, Quasi una fantasia, 1982 : p. 7), la culture populaire a pourtant beaucoup apporté à la musicologie et su inspirer les compositeurs de musique dite "sérieuse"; on relira à cet effet la remarquable démonstration de Pierre Albert Castanet dans son Tout est bruit pour qui a peur - Pour une histoire sociale $d u$ son sale ${ }^{1}$. Cette division latente et persistante a ses conséquences autant sur la musicologie que sur les sciences humaines. Richard Middleton l'a admirablement souligné dans son ouvrage Studying Popular Music paru en 1990. L'analyste y proposait une redéfinition épistémologique des assises et des perspectives de la musicologie classique, laquelle ne parviendrait pas, en raison somme toute de son héritage romantique, à adapter son projet théorique et ses méthodes analytiques dans la compréhension des musiques actuelles. Or des études plus récentes (que l'on songe notamment à celles de David Brackett, Walter Everett, Simon Frith, Allan Moore, Serge Lacasse, Philip Tagg ou de Peter Wicke), si elles relevaient le problème relié à la nécessité d'un nouveau questionnement des principes de la musicologie, elles le transcendaient surtout par des analyses particulièrement stimulantes et vivifiantes d'œuvres de musique populaire, desquelles découlent des propositions théoriques constituant à présent le caractère multidisciplinaire de l'étude de la musique populaire : les études culturelles incluant les Popular Music Studies, l'économie, l'esthétique, l'historiographie, la musicologie, la sémiologie, la sociologie ou encore la technologie.

Le présent numéro d'Intersections souhaiterait mettre en lumière cet essor en présentant les travaux récents de chercheurs, musicologues, créateurs et sociologues de la musique, dont les approches analytiques visent à développer des méthodes adaptées au corpus de la musique populaire avec un regard tourné vers l'anthropologie, la technologie ou l'histoire sociale. Leurs réflexions permettront ainsi au lecteur d'entendre toute la diversité et l'actualité des perspectives pour l'étude de la musique populaire. Il pourra également élargir sa compréhension des relations entre la musique et d'autres formes d'interaction

1 «L'univers Pop et son ombre», Paris, Michel de Maule, 1999, rééd. 2007 : p. 96-103. 
humaine, telle que l'industrie culturelle, la technologie, les identités sociales et/ou ethniques.

Mais à la lecture de ces lignes, c'est encore et malgré tout prendre conscience d'un fait bien réel : la musique populaire a du mal à négocier les transformations industrielles (notamment celles liées au numérique) imposées par une économie marchande, globalisée et soumise aux lois du capitalisme généralisé. Fort heureusement, des irréductibles ouvrent des fenêtres vers un déploiement nouveau de projets coopératifs, créatifs, transgressant les règles établies, l'ordre marchand pour ainsi se rapprocher d'une pratique du don afin de tisser du lien social. En ces temps bousculés, les observations de Marcel Mauss sont des motifs solides et forts utiles dont la finalité reste un viatique.

Toute l'équipe se joint à moi pour souhaiter la bienvenue à la musicologue Florence Leyssieux en tant que secrétaire de rédaction. Ce poste était jusqu'ici occupé par Martine Rhéaume, partie relever de nouveaux défis. Nous lui adressons notre meilleur souvenir et de très belles réussites. 